\title{
Localization and Sizing of UPFC: A Hybrid Optimization Algorithm for Solving Reactive Power Dispatch
}

\author{
Shilpa S. Shrawane Kapse \\ L.T.CO.E, \\ Navi Mumbai, Maharashtra \\ shilpashrawanekapse@gmail.com
}

\author{
Dr. Manoj B. Daigavane \\ G.H.R.I.E.T.W. \\ Nagpur, Maharashtra, India
}

\author{
Dr. Prema M. Daigavane \\ Department of Electrical Engineering \\ G.H.R.C.E. \\ Nagpur, Maharashtra,India
}

\begin{abstract}
In this paper, a method to determine the multi-objective ORPD issue in an unbalanced bus system is presented. In contrast to conventional ORPD issue, the proposed method attains the improvement in voltage enhancement, maximization in loadability, enhancement in ATC, minimization of loss under the unbalanced criteria. In order to determine the optimal positioning and sizing of the UPFC, the ORPD is accomplished by utilizing a hybrid CSA and GWO algorithm. Finally, the simulation outcomes on the benchmark IEEE test bus systems under unbalanced conditions reveal the ORPD performance of the proposed method against the conventional methods. Even under the overloading circumstances, the proposed method has shown its performance in retaining an optimal trade-off between the multiple objectives. Here, the analysis also comprises an examination of the sensitivity of the method over the overloading conditions of the bus system. At last, the simulation outcomes assure that the proposed method is better than the traditional methods such as GWO and CSA.
\end{abstract}

Keywords: ORPD, FACTS, UPFC, ATC, Optimization Algorithm

\begin{tabular}{ll} 
Nomenclature & \\
\hline Abbreviations & Descriptions \\
\hline FACTS & Flexible AC transmission systems \\
TCSC & Thyristor Controlled Series Compensator \\
ABC & Artificial Bee Colony \\
SSR & Subsynchronous Resonance \\
SVC & Static Var Compensator \\
TS & Tabu Search \\
TCPAR & Thyristor Controlled Phase Angle Regulator \\
EP & Evolutionary Programming \\
GA & Genetic Algorithm \\
STATCOM & Shunt Capacitors Static Synchronous Compensators \\
SA & Simulated Annealing \\
ORPD & Optimal Reactive Power Dispatch \\
DE & Differential Evolution \\
SPMOEA & Strength Pareto Multi-Objective Evolutionary Algorithm \\
WWO & Water Wave Optimization \\
PSO & Particle Swarm Optimization \\
O\&M & Operation \& Maintenance \\
LTC & Load Tap Changes \\
CH & Constraint Handling \\
PSOGA & PSO and Gravitational Search Algorithm \\
SMORPD & Stochastic Multi-Objective ORPD \\
ISSO & Improved Social Spider Optimization \\
NDSPSO & Non-Dominated Sorting PSO \\
RPL & Real Power Losses \\
SVSM & Static Voltage Stability Margin \\
LVDN & Load Voltage Deviation \\
WF & Wind Farms \\
GWO & Grey wolf optimizer \\
CSA & Crow Search Algorithm \\
\hline
\end{tabular}




\section{Introduction}

In the power system, the ORPD is considered as a significant tool to attain a safe and economic operation. The main aim of the ORPD problem [15] [16] solution is to reduce a selected objective function like voltage deviation or power loss exploiting the best adjustment of the power system control variables [10], [11]. Generally, the solution for the economic dispatch crisis is attained as the active power outputs of generators. To decrease the cost of generating electric power, the economic dispatch problem solution is utilized.

By exploiting transmission technology named FACTS [12] [13], the stability and the voltage profile of the transmission systems and the power transfer ability of long-distance largely loaded transmission line network are enhanced. Several years, the FACTS devices application [22] [23] [24] is utilized to maximize the use of conventional transmission facilities within the appropriate consistency criteria, solution for loop flow and SSR problem and Stability problem. Nevertheless, to examine the impact of the FACTS devices limited attempt is performed on enhancing the static performance of the system like minimization of loss and cost. ORPD formulation in [9], the FACTS devices are represented as supplementary control parameters. In [9], the static model of three FACTS devices such as TCSC, SVC, and TCPAR is utilized. By finding appropriate values for FACTS devices the reduction of the transmission loss is attained beside with other control variables in the innovative ORPD issue namely transformer tap settings and reactive power generation to adjust reactive power flow in the system [20] [21].

The ORPD [16] [17] is non-convex, multimodal, as well as non-linear optimization issue and it rigorously based upon the primary assumption [14]. To create a global optimal solution, the traditional approaches are incapable and to overcome these meta-heuristic approaches are developed amid that a few are EP, GA, PSO, SA, TS, DE, and ABC and so on. In recent times, a harmony search algorithm HSA has presented system using STATCOM for simultaneous reduction of the power loss, total cost, as well as voltage deviation of IEEE 30-bus test.

By optimization algorithms [17], [35], [36], and [37] the unbalanced distribution systems are identified to be described in the literature in recent times. On the other hand, the RPD problem [18] [19] is handled by quadratic programming over an important unbalanced environment. Although, the quadratic programming is recognized for its precise, computational incompetent that is unable to handle the multiobjective environment. Through the initiation of other cost and security constraints namely installation cost, and voltage profile the problem domain becomes multifaceted.

Contribution: This paper determines the ORPD issues by means of solving the best location and size of UPFC under unbalanced conditions. Then, a state of multiple objectives are examined by that ORPD is attained, besides the maximization of loadability, minimization of system losses and voltage deviation with reduced operating costs of UPFC. Here it is determined by means of the proposed optimization HGWOCS Algorithm.

This paper has the following sections: Section 2 summarizes the ORPD problem issue and Section 3 defines the problem formulation for reactive power dispatch. Section 4 narrates multi-objective function adopted for optimal placement and sizing of UPFC. Section 5 reports the results and Section 6 states the conclusion of the paper.

\section{Literature Review}

In 2017, Zhifang Yang et al [2] developed a new solution to the ORPD issue. A novel ensuing linear estimate method was utilized in order to handle the nonlinearity of the power flow equations. The linear modeling of shunt capacitors was exploited in order to enhance the mathematical transformation of facilitating and accuracy for the voltage magnitude terms. The discrete variables were exploited to model the shunt capacitors and LTCs by using the linear constraints in order to maintain without loss of accuracy. Moreover, it assists the formulation of ORPD model using linearly-constrained mixed-integer. Subsequently, they have instigated an efficient iterative solving method. The power flow solution was austerely satisfied by the attained solution. Finally, the various studies on IEEE benchmark system reveal that the presented algorithm effectively offer an error of the objective functions with near-optimal solutions, which was minimum than $0.1 \%$. Furthermore, the proposed algorithm exhibits various benefits regarding both the efficiency and robustness by comparing the proposed algorithm with various commercial solvers.

In 2018, Partha P. Biswas et al [3] presented two standard bus systems for deterministic ORPD solutions only with thermal generators. Consequently, the scenario-based method was utilized in order to present the stochastic ORPD solution and formulation, which integrates uncertain load demand, solar as well as wind power. For the optimization tasks in all instances, the SHADE method was tested. Moreover, an appropriate restraint handling approach ( $\varepsilon$-constraint) of EAs was effectively incorporated with the 
proposed method. By exploiting basic configurations of the two test systems, the efficacy of a proper $\mathrm{CH}$ method was introduced with the experimented instances. In comparison with the previous examination, the status of all the network limitations was demonstrated, and the outcomes were significantly examined over limitation infringement. Further, the presented SHADE-EC was an efficient method for constrained optimization issues. It rapidly makes the search procedure to the ariable region as well as after that assures rapid convergence to global optima.

In 2018, Jordan Radosavljevi et al [4] worked on ORPD, which were the main significant circumstances in electric power system for security as well as economic operation. To augment the voltage profile as well as minimize the real power loss of the power system, the ORPD was attained using suitable coordination of the equipment that deals with the reactive power flow. Scientifically, with the assistance of various constraints, the ORPD issue can be created as a nonlinear optimization issue. For solving various issues in ORPD, a hybrid PSOGSA method was presented in this paper. Finally, the outcomes attained by the proposed algorithm were compared with conventional meta-heuristic optimization algorithms on standard IEEE 30-bus and 118-bus test systems.

In 2018, Yongquan Zhou [5] developed a WWO approach to resolving the ORPD issue in power system with discrete and continuous control. Here, the ORPD issue was distinct as a discrete, complex, constrained nonlinear combinatorial optimization issue. In order to detect the optimized values of control variables like generator voltages, tap positions of tap changing transformers, as well as the number of reactive compensation devices use the WWO method, which achieves the reduced value for active power losses. In fact, the proposed method efficiently shuns the inadequacy of local search and deprived computation accurateness as well as to discover the global optimal resolution the proposed approach accelerates the convergence rate. Finally, the proposed approach experimented on standard IEEE 30-bus power system, which was to confirm the efficiency and viability of the proposed method in order to undertake with the ORPD issue.

In 2016, Thang Trung Nguyen and Dieu Ngoc Vo [6] developed an ISSO approach in order to attain various objectives of ORPD. Moreover, the developed ISSO approach was presented by exploiting two variations in new solution generation procedure. In order to make the primary and the secondary new solution generation, the developed approach utilizes only one modified equation. However, for each procedure, the standard SSO exploits two equations. The benchmark optimization functions such as IEEE 30 and the 118-bus system was exploited so as to assure the enhancement of the proposed approach. Finally, the attained outcomes of the proposed approach were compared with the existing methods. Similarly, the proposed method exhibits that the proposed method has the ability to identify higher quality extra favorable solutions; also it has the ability to stabilize solution search function.

In 2018, K. Balamurugan and K. Muthukumar [7], presented a heuristic optimization algorithm named as DE method. By contingency analysis, this method was exploited in the deregulated electricity market to solve the optimal position of FACTS devices. Moreover, the FACTS devices were exploited by the proposed method to deal with the optimal injection of reactive and real power. The crossover parameters, as well as the scaling factors, were empirically chosen to improve the search behavior of the DE method. Similar optimization issue was solved by exploiting evolutionary programming approach so as to exhibit the advantage of the proposed method as well as to demonstrate its novelty. Finally, the outcome of the proposed method shows that it was better than the conventional methods with respect to the convergence rate, final solution quality, robustness, and effectiveness.

In 2017, Amin Safari et al [8] developed a new technique for multi-type optimal placement for FACTS devices and it was exploited to optimize multi-objective voltage stability issue. By adopting the multiobjective optimization method called SPMOEA, the present study confers a method for setting and locating of TCSC and SVC. While optimally locating multi-type FACTS devices, three objective functions such as minimizations of RPL, maximization of the SVSM and LVD were considered. Moreover, the IEEE 30- and 118-bus test systems were simulated to validate the efficiency and the performance of the proposed method. At last, the proposed technique was compared with the NSPSO method it exhibits the value of the multi-objective proposed approach.

In 2017, Seyed Masoud Mohseni-Bonab and Abbas Rabiee [1] presented an SMO-ORPD model in wind and load power generation uncertainties. In order to deal with the uncertainties, a two-stage stochastic method was utilized. The RPLs and O\&M cost of WFs were represented as objective functions. The voltage stability index that is Lmax index was considered in order to solve the issue in SMO-ORPD. In addition, find the optimal compromise solution both the fuzzy satisfying and $\varepsilon$-constraint methods were utilized. Here, the reactive power compensation devices were constructed as the discrete control variables. Therefore, the proposed issue was constructed as a mixed-integer non-linear programming optimization issue. 


\section{Problem Formulation for Reactive Power Dispatch}

\subsection{Loss Sensitive Index (LSI) Model}

The LSI [25] offers a significant choice on the reactive and active power losses, which concern the distributed systems and that are mentioned in eq. (1). In eq. (1), MLI and NLI are the real and the reactive power loss indices.

$$
\mathrm{LSI}=\sqrt{\mathrm{MLI}^{2}+\mathrm{NLI}^{2}}
$$

When UPFC is available, $\mathrm{M}_{\mathrm{UPFC}}(\mathrm{i})$ indicate the real power loss as stated in eq. (2) and as in eq. (3) $\mathrm{N}_{\text {UPFC }}(\mathrm{i})$ indicate the reactive power loss, which is generated at the $i^{\text {th }}$ bus.

$$
\begin{aligned}
\mathrm{MLI} & =\sum_{\mathrm{i}=1}^{\mathrm{N}_{\mathrm{B}}} \frac{\mathrm{M}_{\mathrm{UPFC}}(\mathrm{i})}{\mathrm{M}_{\mathrm{L}}(\mathrm{i})} \\
\mathrm{NLI} & =\sum_{\mathrm{i}=1}^{\mathrm{N}_{\mathrm{B}}} \frac{\mathrm{N}_{\mathrm{UPFC}}(\mathrm{i})}{\mathrm{N}_{\mathrm{L}}(\mathrm{i})}
\end{aligned}
$$

However, UPFC is not present $\mathrm{M}_{\mathrm{L}}(\mathrm{i})$ indicates the real power loss and $\mathrm{N}_{\mathrm{L}}(\mathrm{i})$ indicates the reactive power losses, which are generated at the $\mathrm{i}^{\text {th }}$ bus. If the UPFC needs to place or size in the best process is revealed, then these losses can be able to alleviate. Minimizing the losses such as $\mathrm{M}_{\mathrm{UPFC}}$ and $\mathrm{N}_{\mathrm{UPFC}}$ tends to a minimum LSI and therefore, the performance of the system can be enhanced.

\subsection{Voltage Deviation Index (VDI) Model}

Being inspired by the approximations presented in [26], under the balance condition this paper tries to reduce the voltage deviation of the system. By exploiting eq. (4), the voltage magnitude, the unbalanced case, is calculated.

$$
\left|\overline{\mathrm{EV}}_{\mathrm{k}}\right|^{2}=\left|\mathrm{EV}_{\mathrm{i}}\right|^{2}-2\left(\widetilde{\mathrm{r}}_{\mathrm{ik}} \mathrm{M}_{\mathrm{ik}}+\widetilde{\mathrm{x}}_{\mathrm{ik}} \mathrm{N}_{\mathrm{ik}}\right)+\mathrm{c}_{\mathrm{ik}}^{\mathrm{u}}(\mathrm{M}, \mathrm{N})
$$

Eq. (5) and (6) represents the $c_{\mathrm{ik}}^{\mathrm{u}}, \tilde{\mathrm{r}}_{\mathrm{ik}}$ and $\tilde{\mathrm{x}}_{\mathrm{ik}}$. Here, $\mathrm{EV}_{\mathrm{i}}$, indicates the sending end voltage, $\mathrm{M}_{\mathrm{ik}}$ indicates the real power flow and $\mathrm{N}_{\mathrm{ik}}$ indicates the reactive power flow in the line segment from i to $\mathrm{k}$.

$$
\begin{aligned}
& \tilde{r}_{\mathrm{ik}}=\operatorname{Re}\left(a a^{\mathrm{H}}\right) \circ \mathrm{r}_{\mathrm{ik}}+\operatorname{Im}\left(a a^{\mathrm{H}}\right) \circ \mathrm{x}_{\mathrm{ik}} \\
& \tilde{\mathrm{x}}_{\mathrm{ik}}=\operatorname{Re}\left(\mathrm{aa}^{\mathrm{H}}\right) \circ \mathrm{x}_{\mathrm{ik}}-\operatorname{Im}\left(\mathrm{aa}^{\mathrm{H}}\right) \circ \mathrm{r}_{\mathrm{ik}} \\
& \mathrm{a}=\left[\begin{array}{lll}
1 & \mathrm{e}^{-\mathrm{j} 2 \pi / 3} & \mathrm{e}^{\mathrm{j} 2 \pi / 3}
\end{array}\right]^{\mathrm{T}} \\
& \mathrm{c}_{\mathrm{ik}}^{\mathrm{u}}(\mathrm{M}, \mathrm{N})=\left[\mathrm{z}_{\mathrm{ik}}\left[\mathrm{S}_{\mathrm{ik}}^{*} \circ \mathrm{EV}_{\mathrm{i}}^{*}\right] / \mathrm{z}_{\mathrm{ik}}^{*}\left[\mathrm{~S}_{\mathrm{ik}_{0}} \circ \mathrm{EV}_{\mathrm{i}}\right]\right. \\
& \hat{\mathrm{z}}_{\mathrm{ik}}=\hat{\mathrm{r}}_{\mathrm{ik}}+\mathrm{j} \hat{\mathrm{x}}_{\mathrm{ik}} \\
& \hat{\mathrm{z}}_{\mathrm{ik}}=\mathrm{z}_{\mathrm{ik}} \circ\left(\overline{\mathrm{a}}_{\mathrm{i}} \overline{\mathrm{a}}_{\mathrm{i}}^{\mathrm{H}}\right) \\
& \hat{\mathrm{r}}_{\mathrm{ik}}=\operatorname{Re}\left\{\overline{\mathrm{a}}_{\mathrm{i}} \overline{\mathrm{a}}_{\mathrm{i}}^{\mathrm{H}}\right\} \circ \mathrm{r}_{\mathrm{ik}}-\operatorname{Im}\left\{\overline{\mathrm{a}}_{\mathrm{i}} \overline{\mathrm{a}}_{\mathrm{i}}^{\mathrm{H}}\right\} \circ \mathrm{x}_{\mathrm{ik}} \\
& \hat{\mathrm{x}}_{\mathrm{ik}}=\operatorname{Re}\left\{\overline{\mathrm{a}}_{\mathrm{i}} \overline{\mathrm{a}}_{\mathrm{i}}{ }^{\mathrm{H}}\right\} \circ \mathrm{x}_{\mathrm{ik}}+\operatorname{Im}\left\{\overline{\mathrm{a}}_{\mathrm{i}} \overline{\mathrm{a}}_{\mathrm{i}}{ }^{\mathrm{H}}\right\} \circ \mathrm{r}_{\mathrm{ik}} \\
& \mathrm{S}_{\mathrm{ik}}^{\mathrm{l}}=\left[\mathrm{M}_{\mathrm{ik}}+\mathrm{jN} \mathrm{N}_{\mathrm{ik}}\right] \circ\left[\hat{\mathrm{z}}_{\mathrm{ik}}\left(\mathrm{M}_{\mathrm{ik}}-\mathrm{j} \mathrm{N}_{\mathrm{ik}}\right)\right] \\
& \overline{\mathrm{a}}_{\mathrm{i}}=\left[\begin{array}{lll}
1 & \mathrm{e}^{-\mathrm{j} 2 \pi / 3} & \mathrm{e}^{\mathrm{j} 2 \pi / 3}
\end{array}\right]^{\mathrm{T}} / \mathrm{EV}_{\mathrm{R}}
\end{aligned}
$$

From the above eq. (5) to (14), / indicates the element-wise division and $\circ$ indicates the element-wise multiplication of the matrices. The $\overline{\mathrm{EV}}_{\mathrm{k}}$ bus voltages do not show many changes from their preset values. If that kind of changes leads to happen, subsequently they need to be reduced. Therefore, the objective function exploits control the voltage or reduce the changes, which are happening at the load buses, is stated as eq. (15).

$$
\mathrm{EVDI}_{\mathrm{k}}=\rho\left[\Psi\left(\mathrm{EV}_{\text {min }}-\overline{\mathrm{EV}}_{\mathrm{kk}}\right)+\Psi\left(\overline{\mathrm{EV}}_{\mathrm{k}}-\mathrm{EV}_{\text {max }}\right)\right]
$$

\subsection{Available Transfer Capability (ATC) Model}

For the ATC computation, the literature has been discovered a lot of methods [27]. This kind of methods comes under two major categorizations such as methods depend on the CPF and methods depend on the distribution factors. The CPF study permits the calculation of the highest value that denotes the scalar 
parameter related to the linear function of the modifications, which takes place on the nodal inputs of a bus group [28]. However, CPF really states to attain highest loadability, and the CPF possess the capability to adjust all kinds of application, without infringing its regulations. In the primary stage, the $\mathrm{CPF}$ starts and attains the load increment, which is done by utilizing the factor, until the occasion of an exact system limit. While a definite source/sink transmit is measured, the ATC calculation is added as the highest power transmit, which evades the crossing of limits above the base case.

$$
\begin{aligned}
& \mathrm{P}_{\mathrm{L}_{\mathrm{i}}}=\mathrm{P}_{\mathrm{g}_{\mathrm{i}}}-\mathrm{P}_{\mathrm{D}_{\mathrm{i}}} \\
& \mathrm{Q}_{\mathrm{L}_{\mathrm{i}}}=\mathrm{Q}_{\mathrm{g}_{\mathrm{i}}}-\mathrm{Q}_{\mathrm{D}_{\mathrm{i}}} \\
& \mathrm{P}_{\mathrm{c}_{\mathrm{i}}}=\sum_{\mathrm{k}=1}^{\mathrm{N}_{\mathrm{B}}}\left|\mathrm{V}_{\mathrm{i}}\left\|\mathrm{V}_{\mathrm{k}}\right\| \mathrm{Y}_{\mathrm{ik}}\right| \cos \left(\delta_{\mathrm{ik}}-\theta_{\mathrm{ik}}\right) \\
& \mathrm{Q}_{\mathrm{c}_{\mathrm{i}}}=\sum_{\mathrm{k}=1}^{\mathrm{N}_{\mathrm{B}}}\left|\mathrm{V}_{\mathrm{i}}\left\|\mathrm{V}_{\mathrm{k}}\right\| \mathrm{Y}_{\mathrm{ik}}\right| \sin \left(\delta_{\mathrm{ik}}-\theta_{\mathrm{ik}}\right)
\end{aligned}
$$

By exploiting eq. (20) to eq. (23), and eq. (24) - eq. (27) determines the diagonal elements and the offdiagonal elements of the matrix by $m=1,2, \ldots, 2 \mathrm{~N}_{\mathrm{B}}+2$. The $\mathrm{H}_{u u}$ and $\mathrm{L}_{\mathrm{uu}}$ is to $10^{20}$, and it modifies the Jacobean elements of the slack bus and the generator buses. By utilizing eq. (28) to (31), the RHS vector is created.

$$
\begin{aligned}
& \mathrm{F}_{\mathrm{uu}}=\frac{\partial \mathrm{P}_{\mathrm{u}}}{\partial \delta_{\mathrm{u}}}=-\mathrm{N}_{\mathrm{u}}-\mathrm{A}_{\mathrm{uu}}\left|\mathrm{EV}_{\mathrm{u}}\right|^{2} \\
& \mathrm{Q}_{\mathrm{uu}}=\frac{\partial \mathrm{M}_{\mathrm{u}} \cdot\left|\mathrm{EV}_{\mathrm{u}}\right|}{\partial \mathrm{EV}_{\mathrm{u}}}=\mathrm{M}_{\mathrm{u}}+\mathrm{E}_{\mathrm{uu}}\left|\mathrm{EV}_{\mathrm{u}}\right|^{2} \\
& \mathrm{P}_{\mathrm{uu}}=\frac{\partial \mathrm{N}_{\mathrm{u}}}{\partial \delta_{\mathrm{u}}}=\mathrm{P}_{\mathrm{u}}-\mathrm{E}_{\mathrm{uu}}\left|\mathrm{EV}_{\mathrm{u}}\right|^{2} \\
& \mathrm{~L}_{\mathrm{uu}}=\frac{\partial \mathrm{N}_{\mathrm{u}} \cdot\left|\mathrm{EV}_{\mathrm{u}}\right|}{\partial \mathrm{EV}_{\mathrm{u}}}=\mathrm{N}_{\mathrm{u}}-\mathrm{A}_{\mathrm{uu}}\left|\mathrm{EV}_{\mathrm{u}}\right|^{2} \\
& \mathrm{~F}_{\mathrm{uv}}=\frac{\partial \mathrm{M}_{\mathrm{u}}}{\partial \delta_{\mathrm{v}}}=\left|\mathrm{EV}_{\mathrm{u}}\right|\left|\mathrm{EV}_{\mathrm{v}}\right|\left(\mathrm{E}_{\mathrm{uv}} \sin \delta_{\mathrm{uv}}-\mathrm{A}_{\mathrm{uv}} \cos \delta_{\mathrm{uv}}\right) \\
& \mathrm{Q}_{\mathrm{uv}}=\frac{\partial \mathrm{M}_{\mathrm{u}}\left|\mathrm{EV}_{\mathrm{v}}\right|}{\partial \mathrm{EV}_{\mathrm{v}}}=\left|\mathrm{EV}_{\mathrm{u}} \| \mathrm{EV}_{\mathrm{v}}\right|\left(\mathrm{E}_{\mathrm{uv}} \cos \delta_{\mathrm{uv}}+\mathrm{A}_{\mathrm{uv}} \sin \delta_{\mathrm{uv}}\right) \\
& \mathrm{P}_{\mathrm{uv}}=\frac{\partial \mathrm{N}_{\mathrm{u}}}{\partial \delta_{\mathrm{v}}}=-\mathrm{Q}_{\mathrm{uv}} \\
& \mathrm{L}_{\mathrm{uv}}=\frac{\partial \mathrm{N}_{\mathrm{u}}\left|\mathrm{EV}_{\mathrm{v}}\right|}{\partial \mathrm{EV}_{\mathrm{v}}}=\mathrm{F}_{\mathrm{uv}} \\
& \mathrm{A}[\mathrm{i}]=\Delta \mathrm{M}_{\mathrm{i}} \\
& \mathrm{A}\left[\mathrm{i}+\mathrm{Q}_{\mathrm{B}}\right]=\Delta \mathrm{N}_{\mathrm{i}} \\
& \delta_{\mathrm{i}}=\delta_{\mathrm{i}}+\Delta \mathrm{X} \\
& \mathrm{EV} \mathrm{V}_{\mathrm{i}}=\mathrm{EV}_{\mathrm{i}}+\left\{\Delta \mathrm{X}_{\mathrm{i}+\mathrm{n}}\right\} \mathrm{EV}_{\mathrm{i}}
\end{aligned}
$$

\subsection{UPFC Model}

The UPFC is considered as the enhanced FACTS device which shows the effectual control in the reactive and the active load flows [29] [30]. Hence, the UPFC infuses reactive power then the LSI and the consistency registers like, ATC and VDI are enhanced considerably. Several ideas, which are attained with the power injection method that applied to UPFC, are shown in eq. (32) to (35).

$$
\begin{aligned}
& \mathrm{M}_{\mathrm{k}}=\mathrm{M}_{\mathrm{ki}}+\sum_{\mathrm{j}=1}^{\mathrm{N}_{\mathrm{g}}}\left|\mathrm{EV}_{\mathrm{k}}\left\|\mathrm{EV}_{\mathrm{j}}\right\| \mathrm{Y}_{\mathrm{kj}}\right| \cos \left(\delta_{\mathrm{k}}-\delta_{\mathrm{j}}-\theta_{\mathrm{kj}}\right) \\
& \mathrm{N}_{\mathrm{k}}=\mathrm{N}_{\mathrm{ki}}+\sum_{\mathrm{j}=1}^{\mathrm{N}_{\mathrm{B}}}\left|\mathrm{EV}_{\mathrm{k}}\left\|\mathrm{EV}_{\mathrm{j}}\right\| \mathrm{Y}_{\mathrm{kj}}\right| \sin \left(\delta_{\mathrm{k}}-\delta_{\mathrm{j}}-\theta_{\mathrm{kj}}\right) \\
& \mathrm{M}_{\mathrm{i}}=\mathrm{M}_{\mathrm{ik}}+\sum_{\mathrm{j}=1}^{\mathrm{N}_{\mathrm{B}}}\left|\mathrm{EV}_{\mathrm{i}}\left\|\mathrm{EV}_{\mathrm{j}}\right\| \mathrm{Y}_{\mathrm{ij}}\right| \cos \left(\delta_{\mathrm{i}}-\delta_{\mathrm{j}}-\theta_{\mathrm{ij}}\right) \\
& \mathrm{N}_{\mathrm{i}}=\mathrm{N}_{\mathrm{ik}}+\sum_{\mathrm{j}=1}^{\mathrm{N}}\left|\mathrm{EV}_{\mathrm{i}}\left\|\mathrm{EV}_{\mathrm{j}}\right\| \mathrm{Y}_{\mathrm{ij}}\right| \sin \left(\delta_{\mathrm{i}}-\delta_{\mathrm{j}}-\theta_{\mathrm{ij}}\right)
\end{aligned}
$$


In [31], the derivation, which is related to the calculation of the active and the reactive power flows through the transmission line are shown. Also, the connection between the $\mathrm{k}^{\text {th }}$ bus and the $\mathrm{i}^{\text {th }}$ bus, which is accomplished with the UPFC set-up are also exhibited. In eq. (36), $\mathrm{EV}_{\mathrm{k}}$ and $\mathrm{EV}_{\mathrm{i}}$ indicates the voltage magnitudes, which correlates to the $\mathrm{k}^{\text {th }}$ bus and the $i^{\text {th }}$ bus. $\mathrm{E}_{\mathrm{p}}$ indicate the conductance of the parallel component and $E_{s}$ indicate the serial component in UPF. $\mathrm{A}_{\mathrm{p}}$ and $\mathrm{A}_{\mathrm{s}}$ indicates to the susceptance of the parallel component and the serial component in UPFC.

$$
\begin{gathered}
\mathrm{M}_{\mathrm{ki}}=\left\{\begin{array}{c}
\left|\mathrm{EV}_{\mathrm{k}}\right|^{2}\left(\mathrm{E}_{\mathrm{p}}+\mathrm{E}_{\mathrm{s}}\right)-\left|\mathrm{EV}_{\mathrm{k}}\right|\left|\mathrm{G}_{\mathrm{p}} \| \mathrm{Y}_{\mathrm{p}}\right| \cos \left(\theta_{\mathrm{p}}-\delta_{\mathrm{k}}+\delta_{\mathrm{p}}\right) \\
-\left|\mathrm{EV}_{\mathrm{k}}\right|\left|\mathrm{EV}_{\mathrm{h}} \| \mathrm{Y}_{\mathrm{s}}\right| \cos \left(\theta_{\mathrm{s}}-\delta_{\mathrm{k}}+\delta_{\mathrm{i}}\right) \\
+\left|\mathrm{EV}_{\mathrm{k}}\right|\left|\mathrm{E}_{\mathrm{s}}\right|\left|\mathrm{Y}_{\mathrm{s}}\right| \cos \left(\theta_{\mathrm{s}}-\delta_{\mathrm{k}}+\delta_{\mathrm{s}}\right)
\end{array}\right. \\
\mathrm{N}_{\mathrm{ki}}=\left\{\begin{array}{c}
-\left|\mathrm{EV}_{\mathrm{k}}\right|^{2}\left(\mathrm{~A}_{\mathrm{p}}+\mathrm{A}_{\mathrm{s}}\right)+\left|\mathrm{EV}_{\mathrm{k}}\right|\left|\mathrm{E}_{\mathrm{p}} \| \mathrm{Y}_{\mathrm{p}}\right| \sin \left(\theta_{\mathrm{p}}-\delta_{\mathrm{k}}+\delta_{\mathrm{p}}\right) \\
+\left|\mathrm{EV}_{\mathrm{k}}\right|\left|\mathrm{EV}_{\mathrm{h}} \| \mathrm{Y}_{\mathrm{s}}\right| \sin \left(\theta_{\mathrm{s}}-\delta_{\mathrm{k}}+\delta_{\mathrm{i}}\right) \\
-\left|\mathrm{EV}_{\mathrm{k}}\right|\left|\mathrm{E}_{\mathrm{s}} \| \mathrm{Y}_{\mathrm{s}}\right| \sin \left(\theta_{\mathrm{s}}-\delta_{\mathrm{k}}+\delta_{\mathrm{s}}\right)
\end{array}\right. \\
\mathrm{M}_{\mathrm{ik}}=\left\{\begin{array}{c}
\left|\mathrm{EV}_{\mathrm{i}}\right|^{2} \mathrm{G}_{\mathrm{s}}-\left|\mathrm{EV}_{\mathrm{i}}\right|\left|\mathrm{E}_{\mathrm{s}} \| \mathrm{Y}_{\mathrm{s}}\right| \cos \left(\theta_{\mathrm{s}}-\delta_{\mathrm{i}}+\delta_{\mathrm{s}}\right) \\
-\left|\mathrm{EV}_{\mathrm{i}}\right|\left|\mathrm{EV}_{\mathrm{f}} \| \mathrm{Y}_{\mathrm{s}}\right| \cos \left(\theta_{\mathrm{s}}-\delta_{\mathrm{i}}+\delta_{\mathrm{k}}\right)
\end{array}\right. \\
\mathrm{N}_{\mathrm{ik}}=\left\{\begin{array}{c}
-\left|\mathrm{EV}_{\mathrm{i}}\right|^{2} \mathrm{~A}_{\mathrm{s}}+\left|\mathrm{EV}_{\mathrm{i}}\right|\left|\mathrm{E}_{\mathrm{s}} \| \mathrm{Y}_{\mathrm{s}}\right| \sin \left(\theta_{\mathrm{s}}-\delta_{\mathrm{i}}+\delta_{\mathrm{s}}\right) \\
+\left|\mathrm{EV}_{\mathrm{i}}\right|\left|\mathrm{EV}_{\mathrm{k}} \| \mathrm{Y}_{\mathrm{s}}\right| \sin \left(\theta_{\mathrm{s}}-\delta_{\mathrm{i}}+\delta_{\mathrm{k}}\right)
\end{array}\right.
\end{gathered}
$$

$\mathrm{Y}_{\mathrm{p}}$ and $\mathrm{Y}_{\mathrm{s}}$ indicates the access of the parallel and the serial component that presented in $\mathrm{UPFC} ; \theta_{s}$ portrays the angle apprehensive with the access that requires the access linked with the line and the access equivalent to the series component in UPFC; $\partial_{\mathrm{p}}$ and $\partial_{\mathrm{s}}$ represents the voltage sources, which have connection with the parallel component and the serial component residing in UPFC. Therefore, $\mathrm{VE}_{\mathrm{p}}$ and $\mathrm{VE}_{\mathrm{s}}$ denotes the voltage source angle, which is associated with the parallel and the serial component of UPFC. One of the main significant tasks is the position and the size of the UPFC should be known. To determine the best size of the UPFC the cost factor $\left(\mathrm{C}_{\mathrm{UPFC}}\right.$ (in USD/KVar)) is represented as the UPFC operating constraint, as denoted in eq. (39).

$$
\mathrm{C}_{\mathrm{UPFC}}=0.0003 \mathrm{Q}_{\text {inj }}^{2}-0.2691 \mathrm{Q}_{\mathrm{inj}}+188.22
$$

Here $Q_{i n j}$ represents the reactive power to be injected by UPFC [32].

\section{Multi-objective Function Adopted for Optimal Placement and Sizing of UPFC}

\subsection{Objective Model}

Under a balanced condition, the proposed objective for ORPD remnants as a multi-objective minimization issue, which is stated in eq. (41).

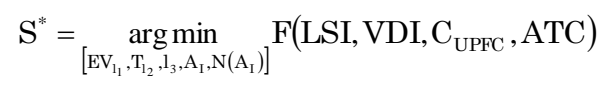

where, $\mathrm{E}\left[\mathrm{V}_{\mathrm{l}_{1}}, \mathrm{~T}_{\mathrm{l}_{2}}, \mathrm{l}_{3}, \mathrm{~A}_{\mathrm{I}}, \mathrm{N}\left(\mathrm{A}_{\mathrm{I}}\right)\right]^{\mathrm{k}}$ indicates the best solution variables. The variables indicate the best voltage to be added, transformer tap settings, shunt capacitance, UPFC position, and the reactive power to be injected. Moreover, four constraints namely VDI, CUPFC, LSI, and ATC are examined. Additionally, utilizing the eq. (42), F(LSI, VDI, $\mathrm{C}_{\mathrm{UPFC}}$, ATC)indicate the multi-objective function can be determined.

$$
\mathrm{F}=\beta_{3} \mathrm{f}_{2}+\frac{1}{\left(1-\beta_{3}\right) \text { ATC }}
$$

In the following sections, the LSI, VDI, $\mathrm{C}_{\mathrm{UPFC}}$ and ATC are the independent objectives that are solved and connected by utilizing the eq. (42), eq. (43) and eq. (44). In spite of solving them independently, as stated in eq. (41) need to integrate an effect on the ultimate objective model, with respect to the scaling factors of the objective functions $\left(\beta_{1}, \beta_{2}\right.$ and $\left.\beta_{3}\right)$.

$$
\begin{aligned}
& f_{2}=\beta_{2} f_{1}+\left(1-\beta_{1}\right) C_{\text {UPFC }} \\
& f_{1}=\beta_{1} L S I+\left(1-\beta_{1}\right) \text { VDI }
\end{aligned}
$$

As stated in eq. (45), the integrated effect of all the objectives is identified. 


$$
\mathrm{F}=\left\{\begin{array}{c}
\alpha(\mathrm{LSI}-\mathrm{VDI})+\left(\frac{\alpha}{\alpha_{1}}\right)\left(\mathrm{VDI}-\mathrm{C}_{\mathrm{upfc}}\right)+ \\
\left(\frac{\alpha}{\alpha_{1} \alpha_{2}}\right) \mathrm{C}_{\text {upfc }}+\frac{1}{1-\left(\frac{\alpha}{\alpha_{1} \alpha_{2}}\right) \mathrm{ATC}}
\end{array}\right.
$$

where $\beta=\beta_{1} \beta_{2} \beta_{3}$, is exploited to reduce the weightage functions which are exploited for each objective in the conventional multi-objective model [39].

\subsection{Conventional optimization GWO Algorithm}

Generally, GWO [33] considered as the new metaheuristics swarm intelligence algorithm. Moreover, GWO is extensively modified for a broad range of optimization issues because of its imposing characteristics over other swarm intelligence approaches. While designing the GWO method, consider the optimal fitness value as $\alpha$, subsequently second and third optimal value as $\beta$ and $\gamma$. Subsequent to finding the prey, the Grey wolves surround and harass the prey until it halts moving. The mathematical model for encircling behavior of grey wolves as mentioned in eq. (46) and (47).

$$
\begin{aligned}
& \overrightarrow{\mathrm{E}}=\left|\overrightarrow{\mathrm{F}} * \overrightarrow{\mathrm{Y}}_{\text {prey }}(\mathrm{t})-\overrightarrow{\mathrm{Y}}_{\mathrm{GW}}(\mathrm{t})\right| \\
& \overrightarrow{\mathrm{Y}}_{\mathrm{GW}}(\mathrm{t}+1)=\overrightarrow{\mathrm{Y}}_{\text {prey }}(\mathrm{t})-\overrightarrow{\mathrm{B}} * \overrightarrow{\mathrm{E}}
\end{aligned}
$$

Where $t$ refers present position, $\overrightarrow{\mathrm{Y}}_{\text {prey }}$ represents the position vector of the prey, $\overrightarrow{\mathrm{Y}}_{\mathrm{GW}}$ depicts the location vector of the grey wolf, $\overrightarrow{\mathrm{B}}$ and $\overrightarrow{\mathrm{E}}$ denotes the coefficient vector and it computed as eq. (49).

$$
\begin{aligned}
& \overrightarrow{\mathrm{B}}=2 \overrightarrow{\mathrm{c}} * \overrightarrow{\mathrm{r}}_{1}-\overrightarrow{\mathrm{c}} \\
& \overrightarrow{\mathrm{E}}=2 * \overrightarrow{\mathrm{r}}_{2}
\end{aligned}
$$

Where, $\vec{c}$ is reduced from 2 to 0 above the way of iterations and are $\vec{r}_{1}$ and $\vec{r}_{2}$ are arbitrary values among 0 and 1. To exactly simulate the hunting behavior of the grey wolf, save the first three optimal fitness values as $\alpha, \beta$ and $\gamma$. These are encompassing potential information regarding the optimum location of the prey.

$$
\begin{aligned}
& \overrightarrow{\mathrm{Y}}_{1}=\overrightarrow{\mathrm{Y}}_{-\alpha}(\mathrm{t})-\overrightarrow{\mathrm{A}}_{2} * \overrightarrow{\mathrm{E}}_{-} \alpha \\
& \overrightarrow{\mathrm{Y}}_{2}=\overrightarrow{\mathrm{Y}}_{-\beta}(\mathrm{t})-\overrightarrow{\mathrm{A}}_{2} * \overrightarrow{\mathrm{E}}_{-} \beta \\
& \overrightarrow{\mathrm{Y}}_{3}=\overrightarrow{\mathrm{Y}}_{-\gamma}(\mathrm{t})-\overrightarrow{\mathrm{A}}_{2} * \overrightarrow{\mathrm{E}}_{-\gamma} \\
& \overrightarrow{\mathrm{E}}_{-\alpha}=\left|\mathrm{F} * \mathrm{Y}_{-\alpha}(\mathrm{t})-\overrightarrow{\mathrm{Y}}_{\mathrm{GW}}(\mathrm{t})\right| \\
& \overrightarrow{\mathrm{E}}_{-\beta}=\left|\mathrm{F} * \mathrm{Y}_{-\beta}(\mathrm{t})-\overrightarrow{\mathrm{Y}}_{\mathrm{GW}}(\mathrm{t})\right| \\
& \overrightarrow{\mathrm{E}}_{-\gamma}=\left|\mathrm{F} * \mathrm{Y}_{-\gamma}(\mathrm{t})-\overrightarrow{\mathrm{Y}}_{\mathrm{GW}}(\mathrm{t})\right|
\end{aligned}
$$

The optimal location of the grey wolf can be computed as in eq. (56).

$$
\mathrm{Y}_{\mathrm{GW}}(\mathrm{t}+1)=\frac{\overrightarrow{\mathrm{Y}}_{1}+\overrightarrow{\mathrm{Y}}_{2}+\overrightarrow{\mathrm{Y}}_{3}}{3}
$$

\subsection{Conventional optimization CSA Algorithm}

The CSA algorithm [34] is an evolutionary method that imitates the activities done by crows for instance recovering and hiding the additional food. It is on the basis of the population; whereas the range of the flock is assured by I folks that are of i dimensional where $i$ is considered as the problem dimension. The position $\mathrm{Y}_{\mathrm{m}, \mathrm{n}}$ of the crow $\mathrm{m}$ is represented as a definite iteration $n$ is represented as a probable result for the problem.

$$
\mathrm{Y}_{\mathrm{m}, \mathrm{n}}=\left[\mathrm{y}_{\mathrm{m}, \mathrm{n}}^{1}, \mathrm{y}_{\mathrm{m}, \mathrm{n}}^{2}, \ldots . \mathrm{y}_{\mathrm{m}, \mathrm{n}}^{\mathrm{n}}\right] ; \mathrm{m}=1,2 \ldots \mathrm{I} ; \mathrm{n}=1,2 \ldots . ., \max \text { itr }
$$

Until the present iteration, each crow is assumed to include the ability to recall the optimal visit position $P_{m, n}$ to keep out of sight the food.

$$
\mathrm{P}_{\mathrm{m}, \mathrm{n}}=\left[\mathrm{p}_{\mathrm{m}, \mathrm{n}}^{1}, \mathrm{p}_{\mathrm{m}, \mathrm{n}}^{2}, \ldots . . \mathrm{p}_{\mathrm{m}, \mathrm{n}}^{\mathrm{n}}\right]
$$


The category of performance represented by each crow $\mathrm{m}$ is indicated by an awareness probability AWP. So, an arbitrary value $a_{i}$ is uniformly distributed among 0 and 1 is sampled. If $a_{\mathrm{i}}$ is $\geq \mathrm{AWP}$, performance 1 is used, else circumstances 2 is selected.

$$
\mathrm{Y}_{\mathrm{m}, \mathrm{n}+1}=\left(\begin{array}{ll}
\mathrm{Y}_{\mathrm{m}, \mathrm{n}}+\mathrm{a}_{\mathrm{i}} \cdot f \mathrm{f}_{\mathrm{m}, \mathrm{n}} \cdot\left(\mathrm{P}_{\mathrm{m}, \mathrm{k}}-\mathrm{Y}_{\mathrm{m}, \mathrm{n}}\right) & \mathrm{a}_{\mathrm{i}} \geq \mathrm{AWP} \\
\text { Random } & \text { otherwise }
\end{array}\right.
$$

The $\mathrm{fl}_{\mathrm{m}, \mathrm{n}}$ is flight length, which denotes the magnitude of movement from crow $\mathrm{Y}_{\mathrm{m}, \mathrm{n}}$ towards the optimal location $\mathrm{P}_{\mathrm{m}, \mathrm{k}}$ of the crow $\mathrm{Y}_{\mathrm{m}, \mathrm{n}}$, the $a_{i}$ is an arbitrary number with uniform distribution within the range of $[0,1]$. The positions of the crows are estimated once the crows are modified, and the memory vector is updated as eq. (60).

$$
\mathrm{P}_{\mathrm{m}, \mathrm{k}+1}=\left(\begin{array}{ll}
\mathrm{O}\left(\mathrm{Y}_{\mathrm{m}, \mathrm{n}+1}\right) & \mathrm{O}\left(\mathrm{Y}_{\mathrm{m}, \mathrm{n}+1}\right)<\mathrm{O}\left(\mathrm{P}_{\mathrm{m}, \mathrm{n}}\right) \\
\mathrm{P}_{\mathrm{m}, \mathrm{k}} & \text { otherwise }
\end{array}\right.
$$

$O(\cdot)$ indicates the objective function to be reduced.

\subsection{Proposed HCSGWO Algorithm}

The existing GWO algorithm is hybridized with the CSA to attain an appropriate balance among exploitation and exploration. By means of it, the optimal sizing and location of UPFC are attained in order to ORPD issues under the balanced conditions. Particularly, the CSA method integrates a control parameter $f_{l}$ in its position updating equation as stated in eq. (59). It permits the search agents to make a decision the magnitude of the step movement to other search agents. It plays an important role in obtaining the global optima as the large value of $f_{l}$, that tend to global exploration when a minimum value of $f_{l}$ outcomes to local exploitation. In the proposed method, instead of updating from $\alpha, \beta$ and $\gamma$, the search agent permits update its position only exploiting $\alpha, \beta$ and $\gamma$ by eq. (61).

$$
\begin{aligned}
& \overrightarrow{\mathrm{Y}}(\mathrm{t}+1)=\frac{\overrightarrow{\mathrm{Y}}+\mathrm{f}_{1} * \operatorname{rand}\left(\left(\overrightarrow{\mathrm{Y}}_{1}-\overrightarrow{\mathrm{Y}}\right)+\left(\overrightarrow{\mathrm{Y}}_{2}-\overrightarrow{\mathrm{Y}}\right)\right)}{2} \\
& \overrightarrow{\mathrm{Y}}(\mathrm{t}+1)=\overrightarrow{\mathrm{Y}}+\mathrm{fl} \times \operatorname{rand} \times\left(\overrightarrow{\mathrm{Y}}_{1}-\overrightarrow{\mathrm{Y}}\right)
\end{aligned}
$$

In this paper, an adaptive balance probability is utilized that permits the proposed method to attain the acceleration during initial steps of optimization process while in the final steps of optimization shows potential solutions is possessed a maximum probability to be used. The adaptive balance probability is calculated as eq. (63).

$$
\mathrm{P}=1-\left(1.01 * \frac{\mathrm{t}^{3}}{\max \text { iter }^{3}}\right)
$$

However, in conventional GWO, the value of $\vec{a}$ is linearly minimized from 2 to 0 as stated in eq. (48). Here, an enhanced approach is revealed in eq. (64) that is used to produce the values for the control parameter $\vec{a}$ at the optimization procedure. It makes the proposed algorithm to efficiently search the search space in comparison to conventional GWO. By eq. (64), the performances of the ORPD can be enhanced. The pseudo-code of the proposed HCSGWO method is described below:

$$
\vec{a}=2-\frac{\cos (\operatorname{rand}() \times 1)}{\text { Max_iter }}
$$

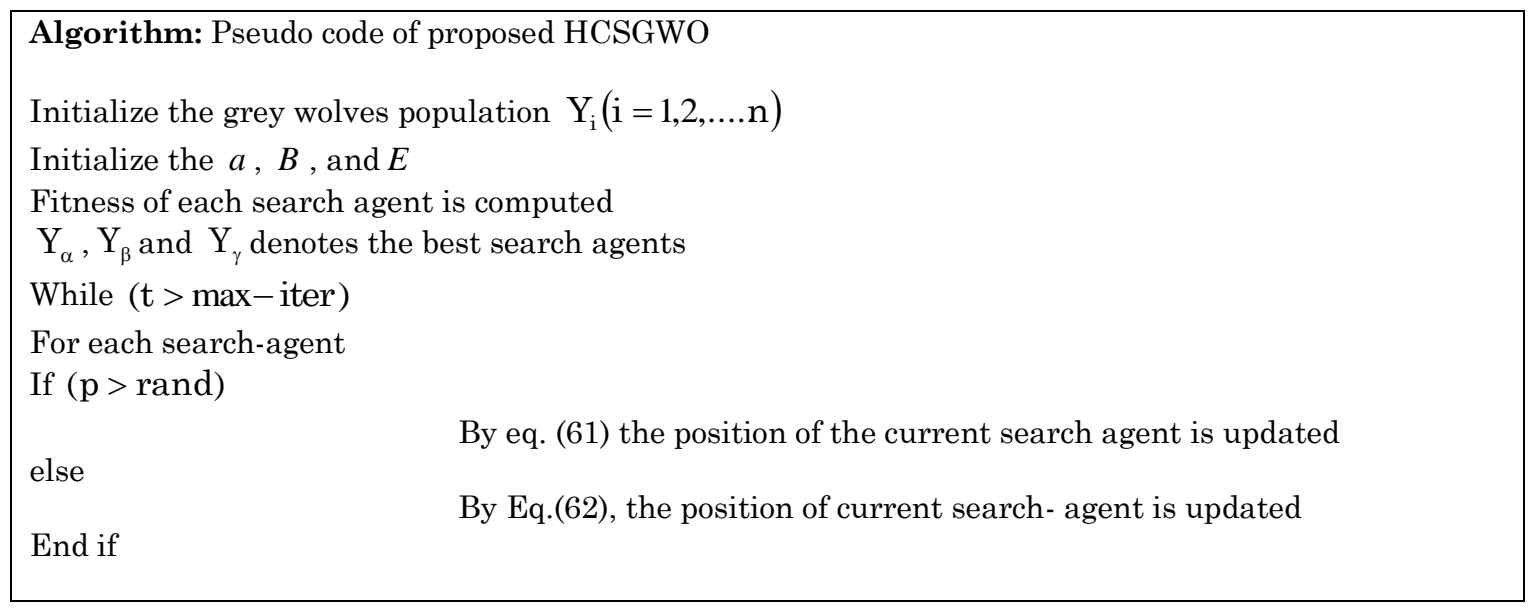




\begin{tabular}{|c|c|}
\hline end for & \\
\hline & By Eq.(63) the value of $\mathrm{P}$ is updated \\
\hline & By eq. (64) the value of 'a' is updated. \\
\hline & Update parameters $B, E$ \\
\hline & The fitness of all search agents is computed. \\
\hline & Update $\mathrm{Y}_{\alpha} \mathrm{Y}_{\beta}$ and $\mathrm{Y}_{\gamma}$ \\
\hline & $\mathrm{t}=\mathrm{t}+1$ \\
\hline end while & \\
\hline & Return $\mathrm{Y}_{\alpha}$ \\
\hline
\end{tabular}

\section{Result and Discussion}

\subsection{Experimental Procedure}

In this paper, the multi-objective ORPD method, as well as the proposed method, has been experimented in MATLAB and the simulations were performed in the IEEE 30, 57 and 118 test bus systems. Here, the experimentation was performed for base case loading, statistical analysis for unbalanced conditions. Then, the testing was extended by overloading five arbitrarily chosen load buses such as $100 \%$, $150 \%, 200 \%, 250 \%, 300 \%, 350 \%$ and $400 \%$ as well as the outcomes were examined. In addition, the proposed method was compared with conventional methods such as CSA and GWO methods.

\subsection{Performance Analysis}

In Table 1, the statistical analysis of the IEEE 30 bus system is demonstrated. Here, the performance of ORPD, the consistency, and reliability of the proposed algorithm is shown. The proposed technique achieved minimum than that the traditional methods. The same performance environment is achieved in VDI. Moreover, the proposed method achieves the minimum mean CUPFC, which is mainly attained in the stochastic procedure. An enhanced ATC is attained by the proposed method when maintaining the evidence of increasing the median and mean ATCs. Hence, in all cases, F also converges to a minimal point, excluding the best-case scenario.

Table 1. Statistical Analysis of the IEEE 30 bus system In the unbalanced state

\begin{tabular}{|c|c|c|c|c|c|c|}
\hline Multi-Objective Functions /Individual & \multicolumn{6}{|c|}{ LSI } \\
\hline Metrics & Best & Worst & Mean & Median & & Std \\
\hline CSA & 22.53 & 20.56 & 22.53 & 18.42 & & 1.932 \\
\hline GWO & 26.79 & 24.08 & 20.14 & 20.56 & & 1.91 \\
\hline HCSGWO & 27.66 & 23.45 & 19.90 & 17.24 & & 1.89 \\
\hline Individual/ Multi-Objective Functions & \multicolumn{6}{|c|}{ VDI } \\
\hline Metrics & Best & Worst & Mean & Median & & Std \\
\hline CSA & 17.93 & 15.86 & 6.08 & 9.22 & & 1.41 \\
\hline GWO & 17.13 & 13.84 & 12.06 & 13.23 & & 0.23 \\
\hline HCSGWO & 18.12 & 13.56 & 12.00 & 13.22 & & 0.22 \\
\hline Individual/ Multi-Objective Functions & \multicolumn{6}{|c|}{$\mathrm{CUPFC}_{\mathrm{UPV}}(\$ / \mathrm{KVAR})$} \\
\hline Metrics & Best & Worst & Mean & Median & & Std \\
\hline CSA & 121.321 & & 122.33 & 142.24 & 3.24 & \\
\hline GWO & 122.341 & & 118.34 & 122.23 & 2.23 & \\
\hline HCSGWO & 124.561 & & 115.26 & 112.45 & 2.01 & \\
\hline Individual/ Multi-Objective Functions & \multicolumn{6}{|c|}{ ATC (MW) } \\
\hline Metrics & Best & Worst & Mean & Median & & Std \\
\hline CSA & 19.221 & & 18.32 & 15.23 & 1.23 & \\
\hline GWO & 18.121 & & 18.22 & 15.34 & 1.67 & \\
\hline HCSGWO & 20.221 & & 16.23 & 17.22 & 1.02 & \\
\hline Individual/ Multi-Objective Functions & \multicolumn{6}{|c|}{ MULTI-OBJECTIVE FUNCTION F $\left(\times 10^{-3}\right)$} \\
\hline Metrics & Best & Worst & Mean & Median & & Std \\
\hline CSA & 18.231 & & 14.23 & 6.22 & 1.22 & \\
\hline GWO & 17.221 & & 12.23 & 6.23 & 1.46 & \\
\hline HCSGWO & 20.231 & & 10.22 & 5.33 & 1.20 & \\
\hline
\end{tabular}

Table 2 exhibits the performance analysis of the conventional and proposed approach in IEEE 57 Bus system. Here, the proposed method minimized the VDI, LSI, and F than the conventional methods under base case loading. The enhancement shown by the proposed approach is far better than the existing 
approaches LSI as well as VDI over the base case loading. The proposed method has minimized the operating cost of UPFC, and the final cost F remnants better than the existing approaches.

Table 2. Analysis between existing and proposed techniques in IEEE 57 bus test system.

\begin{tabular}{|c|c|c|c|c|c|}
\hline Variable Types & Variables & No ORPD & CSA & GWO & HCSGWO \\
\hline \multirow[t]{15}{*}{ Solution Variables } & $V_{1}$ & 2.14 & 2.03 & 2.14 & 2.02 \\
\hline & $\mathrm{V}_{2}$ & 2.01 & 2.09 & 2.02 & 2.02 \\
\hline & $\mathrm{V}_{3}$ & 1.234 & 2.04 & 2.03 & 2.02 \\
\hline & $\mathrm{V}_{6}$ & 1.98 & 1.06 & 0.99 & 0.97 \\
\hline & $\mathrm{V}_{8}$ & 2.5 & 2.10 & 2.04 & 2.05 \\
\hline & $V_{12}$ & 2.1 & 2.05 & 2.04 & 2.08 \\
\hline & $\mathrm{T}_{19}$ & 1.97 & 1.04 & 1.98 & 1.99 \\
\hline & $\mathrm{T}_{31}$ & 2.3 & 2.95 & 1.10 & 1.06 \\
\hline & $\mathrm{T}_{37}$ & 2.3 & 2.04 & 1.96 & 1.05 \\
\hline & $\mathrm{T}_{41}$ & 1.9 & 2.05 & 1.90 & 1.01 \\
\hline & $\mathrm{C}_{18}$ & 11 & 10.3 & 9.96 & 11.57 \\
\hline & $\mathrm{C}_{25}$ & 7.2 & 8.04 & 12.96 & 11.16 \\
\hline & $\mathrm{C}_{53}$ & 5.3 & 19.5 & 12.74 & 18.57 \\
\hline & BI (UPFC ID) & 5.1 & 6.00 & 4.00 & 3.00 \\
\hline & $Q_{\text {inj }}$ (UPFC sizing) & 0.3 .2 & 0.65 & 0.64 & 0.44 \\
\hline \multirow{3}{*}{$\begin{array}{l}\text { Dependent } \\
\text { variables }\end{array}$} & LSI & 17.86 & 16.6 & 16.47 & 11.55 \\
\hline & VDI & 610.72 & 2.80 & 0.88 & 24.42 \\
\hline & C UPFC ( $\$ /$ KVar $)$ & 12.2 & 18.4 & 18.05 & 188.10 \\
\hline $\begin{array}{l}\text { Multi-objective } \\
\text { function }\end{array}$ & $\bar{F}$ & 4.23 & 45.1 & 44.59 & 41.72 \\
\hline
\end{tabular}

\subsection{Statistical Analysis}

In Table 3, the final cost for various loading states on load buses is shown for IEEE 118 bus system. Here, the experiment is done for different system overloading such as $50 \%, 100 \%, 150 \%, 200 \%, 250 \%, 300 \%$, $350 \%$ and $400 \%$. Moreover, the overall analysis reveals the proposed technique is superior to the existing techniques.

Table 3. Analysis of proposed and Existing approaches under the unbalanced condition for IEEE 118 bus test system

\begin{tabular}{llll}
\hline Overloading (\%) & CSA & GWO & HCSGWO \\
\hline $\mathbf{5 0}$ & 8196.85 & 9262.65 & 7144.45 \\
$\mathbf{1 0 0}$ & 8886.86 & 5515.93 & 4328.24 \\
$\mathbf{1 5 0}$ & 1903.11 & 2281.73 & 1850.24 \\
$\mathbf{2 0 0}$ & 2153.91 & 1958.47 & 1361.10 \\
$\mathbf{2 5 0}$ & 1653.95 & 1858.45 & 1522.10 \\
$\mathbf{3 0 0}$ & 5223.03 & 3377.80 & 2681.14 \\
$\mathbf{3 5 0}$ & 4370.34 & 2938.59 & 2234.32 \\
$\mathbf{4 0 0}$ & 6386.99 & 4426.31 & 3741.27 \\
\hline
\end{tabular}

Table 4 exhibits the statistical report of the IEEE 118 bus system under unbalanced conditions. Here, the proposed method reduces VDI, LSI, and F than conventional methods.

Table 4. Statistical report of the IEEE 118 bus system in the unbalanced condition

\begin{tabular}{|c|c|c|c|c|}
\hline Individual/ Multi-Objective Functions & LSI & & & \\
\hline Metrics & Best Worst & Mean & Median & Std \\
\hline CSA & 110.22100 .22 & 122.33 & 121.33 & 0.22 \\
\hline GWO & 112.2698 .23 & 124.44 & 113.22 & 1.22 \\
\hline HCSGWO & 132.4596 .24 & 121.23 & 112.32 & 0.12 \\
\hline Individual/ Multi-Objective Functions & VDI & & & \\
\hline Metrics & Best Worst & Mean & Median & $\overline{\text { Std }}$ \\
\hline CSA & 121.03111 .23 & 123.32 & 123.78 & 1.23 \\
\hline GWO & 112.03109 .23 & 120.03 & 119.34 & 1.32 \\
\hline HCSGWO & 132.1210 .23 & 119.03 & 111.23 & 0.99 \\
\hline Individual/ Multi-Objective Functions & CupFC $(\$ / \mathrm{KVAR})$ & & & \\
\hline Metrics & Best Worst & Mean & Median & Std \\
\hline CSA & 123.23112 .34 & 123.34 & 128.91 & 2.29 \\
\hline GWO & 122.34109 .23 & 134.62 & 129.34 & 2.23 \\
\hline HCSGWO & 136.23105 .22 & 145.23 & 125.32 & 2.24 \\
\hline Individual/ Multi-Objective Functions & $\operatorname{ATC}(\mathrm{MW})$ & & & \\
\hline Metrics & Best Worst & Mean & Median & Std \\
\hline
\end{tabular}




\begin{tabular}{lllll}
\hline CSA & 125.34112 .34 & 122.32 & 118.22 & 1.23 \\
GWO & 123.34111 .23 & 118.22 & 112.34 & 1.34 \\
HCSGWO & 138.23110 .23 & 112.23 & 110.22 & 0.23 \\
Individual/ Multi-Objective Functions & MULTI-OBJECTIVE FUNCTION F $\left(\times 10^{-3}\right)$ & & \\
\hline Metrics & Best Worst & Mean & Median & Std \\
CSA & 114.23112 .32 & 123.45 & 123.24 & 1.21 \\
GWO & 112.34114 .32 & 132.23 & 111.23 & 1.32 \\
HCSGWO & 132.34112 .12 & 111.23 & 110.12 \\
\hline
\end{tabular}

\section{Conclusion}

In this paper, a multi-objective ORPD issue model was proposed to maintain the regulation of the voltage problems in an unbalanced environment and also to reduce the system losses. Here, the maximum loadability can be attained by means of the derived model because it has the ability to maintain the overloading. This paper presented a hybrid CSA and GWO method in order to determine the multiobjective model. Hence, the proposed technique solved the best system parameters and the best reactive power that requires introduce into the optimal bus of the system. Finally, the simulation outcomes on the benchmark bus system were shown that the proposed method was superior to the traditional methods such as CSA and GWO methods. By means of the various overloading conditions and statistical analysis of the bus system, the effectiveness of the proposed technique was shown. Additionally, the proposed technique was shown the inconsiderate to the overloading restraint. Nevertheless, the scaling factors exploited in the multi-objective function need suitable chosen to enhance the performance of the proposed ORPD technique.

\section{Compliance with Ethical Standards}

Conflicts of interest: Authors declared that they have no conflict of interest.

Human participants: The conducted research follows the ethical standards and the authors ensured that they have not conducted any studies with human participants or animals.

\section{References}

[1] S. M. Mohseni-Bonab and A. Rabiee, "Optimal reactive power dispatch: a review, and a new stochastic voltage stability constrained multi-objective model at the presence of uncertain wind power generation," IET Generation, Transmission \& Distribution, vol. 11, no. 4, pp. 815-829, 932017.

[2] Z. Yang, A. Bose, H. Zhong, N. Zhang, Q. Xia and C. Kang, "Optimal Reactive Power Dispatch With Accurately Modeled Discrete Control Devices: A Successive Linear Approximation Approach," IEEE Transactions on Power Systems, vol. 32, no. 3, pp. 2435-2444, May 2017.

[3] Partha P. Biswas, P. N. Suganthan, R. Mallipeddi, Gehan A. J. Amaratunga,"Optimal reactive power dispatch with uncertainties in load demand and renewable energy sources adopting scenario-based approach", Applied Soft Computing, vol. 75, pp. 616-632, February 2019.

[4] Radosavljevic, J., Jevtic, M. \& Milovanovic,"A solution to the ORPD problem and critical analysis of the results,"Electrical Engineering, vol 100, no 1, pp 253-265,March 2018.

[5] Yongquan Zhou, Jinzhong ZhangXiao, YangYing Ling,"Optimal reactive power dispatch using water wave optimization algorithm",Operational Research,pp 1-17,2018.

[6] Thang Trung, NguyenDieu Ngoc Vo,"Improved social spider optimization algorithm for optimal reactive power dispatch problem with different objectives",Neural Computing and Applications, pp 1-32,2019.

[7] K. Balamurugan, K. Muthukumar,"Differential Evolution algorithm for contingency analysis-based optimal location of FACTS controllers in deregulated electricity market",Soft Computing, vol.23, Issue 1, pp 163179,January 2019.

[8] Amin Safari, Mojtaba Bagheri, Hossein Shayeghi,"Optimal setting and placement of FACTS devices using strength Pareto multi-objective evolutionary algorithm",Journal of Central South University, vol. 24, no. 4, pp 829-839, April 2017.

[9] P. Preedavichit and S. C. Srivastava, "Optimal reactive power dispatch considering FACTS devices," 1997 Fourth International Conference on Advances in Power System Control, Operation and Management, APSCOM97. (Conf. Publ. No. 450), Hong Kong, 1997, pp. 620-625 vol.2.

[10] Radosavljevic J, Klimenta D, Jevtic M, Arsic N," Optimal power flow using a hybrid optimization algorithm of particle swarm optimization and gravitational search algorithm" Electr Power Compon Syst, vol.no 43(17), 2015.

[11] Radosavljevic J, Jevtic M" Solution of optimal reactive power dispatch by a hybrid GSA-SQP algorithm", Elektronika irElektrotechnika, vol. no 22(3), pg no. 3-6, 2016. 
[12] N.G. Hingorani, L. Gyugyi, "Understanding FACTS: concepts and technology of flexible AC transmission systems", New York: IEEE Press, 2001.

[13] F.D. Galiana, K. Almeida, M. Toussaint, J. Griffin, "Assessment and control of the impact of FACTS devices on power system performance”, IEEE Trans Power Syst, vol. 11, no. 4, pp. 1931-6,1996.

[14] H.I. Shaheen, G.I. Rashed, S.J. Cheng, "Application and comparison of computational intelligence techniques for optimal location and parameter setting of UPFC" Eng Appl Art Int, vol. 23, no. 2, pp. 203-16,2010.

[15] Z. Yang, A. Bose, H. Zhong, N. Zhang, Q. Xia and C. Kang, "Optimal Reactive Power Dispatch With Accurately Modeled Discrete Control Devices: A Successive Linear Approximation Approach," in IEEE Transactions on Power Systems, vol. 32, no. 3, pp. 2435-2444, May 2017.

[16] Yong-jun Zhang and Zhen Ren, "Optimal reactive power dispatch considering costs of adjusting the control devices," IEEE Transactions on Power Systems, vol. 20, no. 3, pp. 1349-1356, Aug. 2005.

[17] D. Gutierrez Rojas, J. Lopez Lezama and W. Villa, "Metaheuristic Techniques Applied to the Optimal Reactive Power Dispatch: a Review," IEEE Latin America Transactions, vol. 14, no. 5, pp. 2253-2263, May 2016.

[18] A. Khorsandi, A. Alimardani, B. Vahidi and S. H. Hosseinian, "Hybrid shuffled frog leaping algorithm and Nelder-Mead simplex search for optimal reactive power dispatch,"IET Generation, Transmission \& Distribution, vol. 5, no. 2, pp. 249-256, February 2011.

[19] A. Mukherjee and V. Mukherjee, "Solution of optimal reactive power dispatch by chaotic krill herd algorithm,"IET Generation, Transmission \& Distribution, vol. 9, no. 15, pp. 2351-2362, 19112015.

[20] Q. Li, L. Yang and S. Lin, "Coordination Strategy for Decentralized Reactive Power Optimization Based on a Probing Mechanism," IEEE Transactions on Power Systems, vol. 30, no. 2, pp. 555-562, March 2015.

[21] P. Li, Z. Wu, K. Meng, G. Chen and Z. Y. Dong, "Decentralized Optimal Reactive Power Dispatch of Optimally Partitioned Distribution Networks," IEEE Access, vol. 6, pp. 74051-74060, 2018.

[22] E. Ghahremani and I. Kamwa, "Optimal placement of multiple-type FACTS devices to maximize power system loadability using a generic graphical user interface," IEEE Transactions on Power Systems, vol. 28, no. 2, pp. 764-778, May 2013.

[23] Y. D. Valle, J. Perkel, G. K. Venayagamoorthy and R. G. Harley, "Optimal Allocation of Facts Devices: Classical Versus Metaheuristc Approaches," SAIEE Africa Research Journal, vol. 100, no. 1, pp. 12-23, March 2009.

[24] T. Joseph, C. E. Ugalde-Loo, J. Liang and P. F. Coventry, "Asset Management Strategies for Power Electronic Converters in Transmission Networks: Application to Hvdc and FACTS Devices," IEEE Access, vol. 6, pp. 21084-21102, 2018.

[25] Chandrasekhar Yammani, Sydulu Maheswarapu andSailaja Kumari Matam, "Optimal placement and sizing of distributed generations using shuffled bat algorithm with future load enhancement", International Transactions on Electrical Energy Systems, Vol. 26, No. 2, pp. 274-292, 2016

[26] Brett A. Robbins; Alejandro D. Domínguez-García, "Optimal Reactive Power Dispatch for Voltage Regulation in Unbalanced Distribution Systems", IEEE Transactions on Power Systems, Vol. 31, No. 4, pp. 2903 - 2913,2016

[27] E. Dall'Anese, H. Zhu, and G. Giannakis, "Distributed optimal power flow for smart microgrids," IEEE Trans. Smart Grid, vol. 4, no. 3, pp. 1464-1475, Sep. 2013.

[28] Ghasemi, Mojtaba \& Taghizadeh, Mahdi \& Ghavidel, Sahand \& Aghaei, J \& Abbasian, Abbas," Solving optimal reactive power dispatch problem using a novel teaching-learning-based optimization algorithm" Engineering Applications of Artificial Intelligence 39(2015)100-108.

[29] North American Reliability Council (NERC). Available Transfer Definitions and Determinations. NERC Report, June 1996.

[30] FACTS Overview. Piscataway: IEEE Power Engineering Society/Cigre, IEEE Service Center; 1995 [Special Issue, 95TP108].

[31] Radman G, Raje RS. Power flow model/calculation for power systems with multiple FACTS controllers. Int J Electr Power Syst Res 2007;77:1521-31.

[32] Biplab Bhattacharyya, Vikash Kumar Gupta, Sanjay Kumar, "UPFC with series and shunt FACTS controllers for the economic operation of a power system", Volume 5, Issue 3, September 2014, Pages 775-787.

[33] M. F. Hassanin, A. M. Shoeb and A. E. Hassanien, "Grey wolf optimizer-based back-propagation neural network algorithm," 12th International Computer Engineering Conference (ICENCO), Cairo, pp. 213-218, 2016.

[34] Z. Wu, K. Huang and A. S. Girsang, "A Whole Crow Search Algorithm for Solving Data Clustering," Conference on Technologies and Applications of Artificial Intelligence (TAAI), Taichung, 2018, pp. 152-155,2018.

[35] R Gupta Roy, D Baidya,"Speed Control of DC Motor Using Fuzzy-Based Intelligent Model Reference Adaptive Control Scheme",Advances in Communication, Devices and Networking, Lecture Notes in Electrical Engineering book series, Springer, vol. 462, pp.729-735, 2018.

[36] G Singh, VK Jain, A Singh, "Adaptive network architecture and firefly algorithm for biogas heating model aided by photovoltaic thermal greenhouse system",Energy \& Environment, vol. 29 (7), pp.1073-1097,2018.

[37] A Shankar, J Natarajan,"Base Station Positioning in Wireless Sensor Network to aid Cluster Head Selection Process", International Journal of Intelligent Engineering and Systems", vol. 10, no.(2), pp.173-182, 2017. 